\title{
SISTEM INFORMASI PEMINJAMAN BUKU DI PERPUSTAKAAN MADRASAH IBTIDAIYAH AL-MADINAH
}

\author{
Syifah Atik Fatimah ${ }^{1}$, Dewi Driyani ${ }^{2}$, Ek Ajeng Rahmi Pinahayu ${ }^{3}$ \\ ${ }^{1,2,3}$ Teknik Informatika, Fakultas Teknik dan Ilmu Komputer, Universitas Indraprasta PGRI \\ Jalan Raya Tengah No.80, Kelurahan Gedong, Pasar Rebo, Jakarta Timur \\ 1syifahatikk@gmail.com, ${ }^{2}$ dewi.driyani2@gmail.com, ${ }^{3}$ ekajeng_rahmipinahayu@yahoo.com
}

\begin{abstract}
ABSTRAK
Penulis melakukan penelitian di perpustakaan Madrasah Ibtidaiyah Al-Madinah. Dalam proses peminjaman buku diperpustakaan masih menggunakan manual yaitu melakukan pencatatan dalam buku besar. Oleh karena itu Tujuan dari penelitian ini adalah membuat aplikasi peminjaman buku untuk mempermudah pekerjaan petugas dan transaksi peminjaman. Metode yang digunakan untuk merancang Sistem Informasi Peminjaman Buku ini adalah metode Research and Development (R\&D). File pendukung dalam pembuatan program ini seperti Java dan MySQL. Aplikasi Sistem Informasi Peminjaman buku dapat mempermudah proses penyimpanan data perpustakaan dan mempermudah transaksi perpustakaan sekolah Madrasah Ibtidaiyah AlMadinah.
\end{abstract}

Kata Kunci : Sistem Informasi, Peminjaman, Perpustakaan, Java, dan MySql

\section{ABSTRACT}

The author conducted research in the library of Madrasah Ibtidaiyah Al-Madinah. In the process of borrowing books in the library, they still use manuals, namely recording in the ledger. Therefore, the purpose of this research is to make an application for borrowing books to facilitate the work of officers and borrowers. The method used to design this Book Lending Information System is the Research and Development (R\&D) method. Supporting files in making this program such as Java and MySQL. The Book Borrowing Information System application can simplify the process of storing library data and facilitate transactions for the Madrasah Ibtidaiyah Al-Madinah school library.

Key Word: Information System, Loaning, Library, Java, dan MySql

\section{PENDAHULUAN}

Sekolah Madrasah Ibtidaiyah Al-Madinah merupakan salah satu sekolah islam di Jakarta. Perkembangan ilmu Pengetahuan dan Teknologi, salah satunya di bidang komputer yang berkembang sangat pesat, sehingga mampu mempengaruhi kehidupan sehari-hari. Dengan menggunakan sistem komputerisasi berbasis dekstop yang dapat mempercepat pengolahan data lebih akurat. Sistem terkomputerisasi juga dapat diterapkan pada peminjaman dan pengembalian buku di perpustakaan sekolah.

Proses peminjaman Buku yang dilakukan oleh anggota di suatu perpustakaan menggunakan syarat dan ketentuan yang berlaku di dalam perpustakaan seperti judul buku, jumlah buku, lama pinjam dan pengembalian buku. (Darwati, 2017)

"Sistem adalah komponen yang saling berkaitan untuk mencapai tujuan" (Rifani dkk, 2021). "Informasi adalah data yang telah diolah menjadi data yang berguna dan berarti untuk penerimanya" (Sutopo et al., 2016). "Sistem Informasi adalah kumpulan komponen bekerja sama untuk mencatat data" (Nugraha \& Pramukasari, 2017).

"Basis Data adalah sekumpulan data yang saling berkesinambungan dan terorganisir dengan baik" (Hidayat et al., 2017). "Perpustakaan adalah koleksi grafis atau bahan cetak seperti slide, film, tape, piringan hitam dalam gedung atau ruangan yang di atur dan sistematis untuk keperluan belajar, penelitian, pembacaan" (Rahmawati \& Bachtiar, 2018).

"Java adalah bahasa pemrograman untuk membuat program dokumen HTML dalam browser agar menjadi lebih interaktif dan tidak hanya sekedar indah saja" (Prayitno \& Safitri, 2015). "Netbeans adalah proyek open source IDE yang berbasiskan java oleh Sun Microsystem 
yang berjalan di atas swing" (Putera \& Ibrahim, 2018).

"Xampp adalah sebuah paket kumpulan software yang terdiri dari PhpMyAdmin, Apache, PHP, MySQL, Perl, Filezella dan lainnya." Xampp berfungsi memudahkan instalasi $P H P$ untuk pengembangan web MySQL, PhpMyAdmin,PHP Apache, dan software membuat web. Untuk aplikasi dapat di extract dan diinstal memilih xampp sesuai sistem operasinya" (Hidayat, Marlina, dan Utami, 2017).

Tujuan penelitian yang ingin dicapai dalam Sistem Informasi Peminjaman Buku di Perpustakaan Madrasah ibtidaiyah AlMadinah adalah membuat aplikasi perpustakaan yang sesuai dengan kebutuhan petugas dalam mengelola perpustakaan Madrasah Ibtidaiyah Al-Madinah, meningkatkan kinerja, karena tidak lagi menggunakan sistem manual dalam melaksanakan pengolahan data pada perpustakaan Madrasah Ibtidaiyah AlMadinah, dan untuk merancang sistem informasi agar membantu mengelola laporan data buku, laporan pinjam, laporan pengembalian, laporan siswa, dan laporan denda di Madrasah Ibtidaiyah Al-Madinah menjadi lebih akurat.

Manfaat Penelitian yang ingin dicapai dalam Sistem Informasi Peminjaman Buku di Perpustakaan Madrasah Ibtidaiyah AlMadinah adalah memudahkan Pengembalian dan Peminjaman Buku di Perpustakaan Madrasah Ibtidaiyah AlMadinah dan penyimpanan data-data menjadi lebih aman dan tersimpan dengan rapih serta mudah dicari.

\section{METODE PENELITIAN}

Berdasarkan tujuan dan rumusan masalah di atas, jenis penelitian yang digunakan penulis adalah menggunakan metode Research and Development (R\&D). Menurut (Rumetna, Lina, dan Santosa, (2020) metode Research and Development (R\&D) adalah penelitian yang menggunakan metode untuk menghasilkan produk tertentu, menguji tingkat efektifitas suatu produk dan untuk menyempurnakan suatu produk sesuai dengan acuan. Peneliti melakukan penelitian terlebih dahulu untuk mengumpulkan sejumlah data yang dibutuhkan selanjutnya dilakukan pengembangan sistem dan melakukan pengujian serta evaluasi terhadap sistem yang dibuat.

Penyusunan artikel ini dapat menghasilkan sistem informasi yang diinginkan untuk mempermudah siswa siswi sekolah dalam melakukam peminjaman buku diperpustakaan, serta mempermudah petugas perpustakaan dalam pengolahan data sehingga perpustakaan Madrasah Ibtidaiyah AlMadinah menjadi lebih maju di bandingkan Madrasah-madrasah lainnya.

Penelitian ini dilakukan selama 4 bulan yaitu bulan April sampai dengan Juli 2021. Tempat penulis melakukan penelitian berada di Madrasah Ibtidaiyah Al-Madinah Jl. Tanjung Barat Selatan (Gg 100) Rt 007/Rw001 Tanjung Barat. Telp: (021) 22001752, 081289108096.

\section{HASIL DAN PEMBAHASAN}

Berdasarkan masalah yang terdapat pada perpustakaan sekolah, alternatif penyelesaian masalah yang penulis usulkan yaitu :

1. Membuat aplikasi Sistem Informasi Peminjaman Buku di Perpustakaan Madrasah Ibtidaiyah Al madinah dengan menggunakan bahasa pemprograman Java .

2. Menggunakan database MySql sebagai media penyimpanan data yang digunakan sekolah agar bisa meminimalisir kemungkinan terjadinya kehilangan data.

3. Siswa lebih mudah mendapatkan informasi peminjamn dan pengembalian buku perpustakaan.

4. Petugas perpustakaan memberikan informasi yang berkaitan dengan data peminjaman dan pengembalian buku.

5. Penulis menggunakan plugin Ireport untuk membuat laporan di netbeans.

6. Pengujian tingkat efektivitas sistem peminjaman buku di perpustakaan sudah lebih mudah.

7. Menggunakan acuan Litbang Depdagri, jika rasio efektivitasnya <40 maka tingkat capaian nya sangan tidak efektif, jika rasio 40-59,99 termasuk tidak efektif, jika rasio 60-79,99 termasuk 
cukup efektif, jika rasio >80 maka tingkat capaian nya sangat efektif.

8. Evaluasi yang telah dilakukan saat ini sudah berada pada rasio 60-79,99 dengan tingkat capaian cukup efektif dari yang sebelumnya rasio berada pada 40-59,99 dengan tingkat capaian tidak efektif.

Penulis menggambarkan sistem diusulkan dalam bentuk DFD (Data Flow Diagram) untuk merancang sistem aplikasi. DFD merupakan teknik grafis yang menggambarkan aliran informasi yang di pergunakan saat data bergerak dari input menjadi output Binarso, Sarwoko, dan Bachtiar (2012) sebagai berikut :

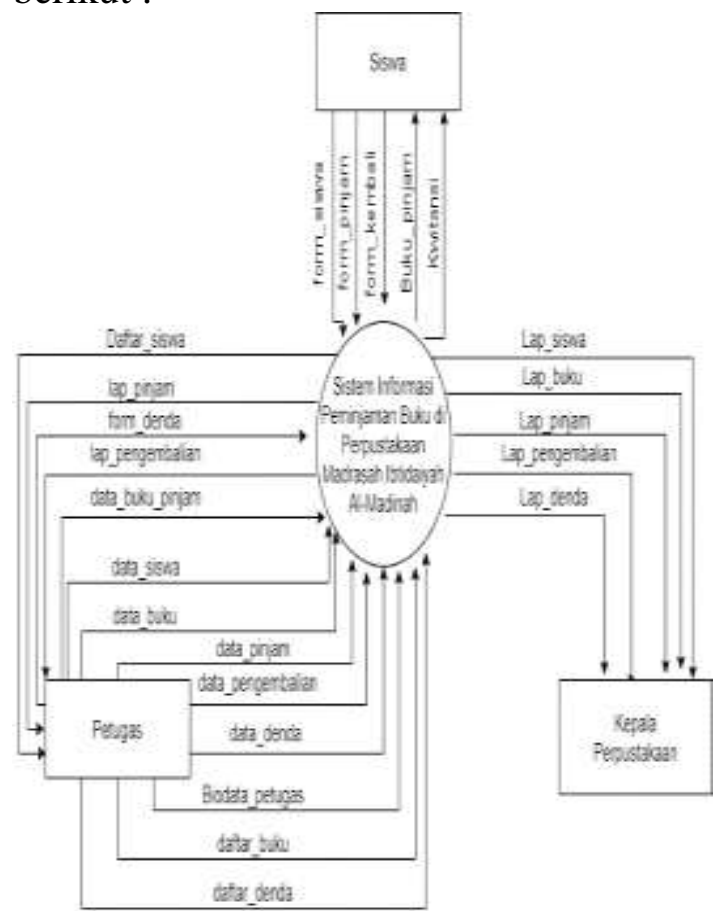

Gambar 1. Diagram Konteks yang Diusulkan

Hubungan antar dua diagram dalam bentuk ERD (Entity Relationship Diagram).

ERD merupakan diagram yang menjadi penghubung antar data. Binarso, Sarwoko, dan Bahtiar (2012). ERD pada penelitian ini terdapat entity sebagai pengguna aplikasi yaitu petugas, siswa, dan kepala sekolah.

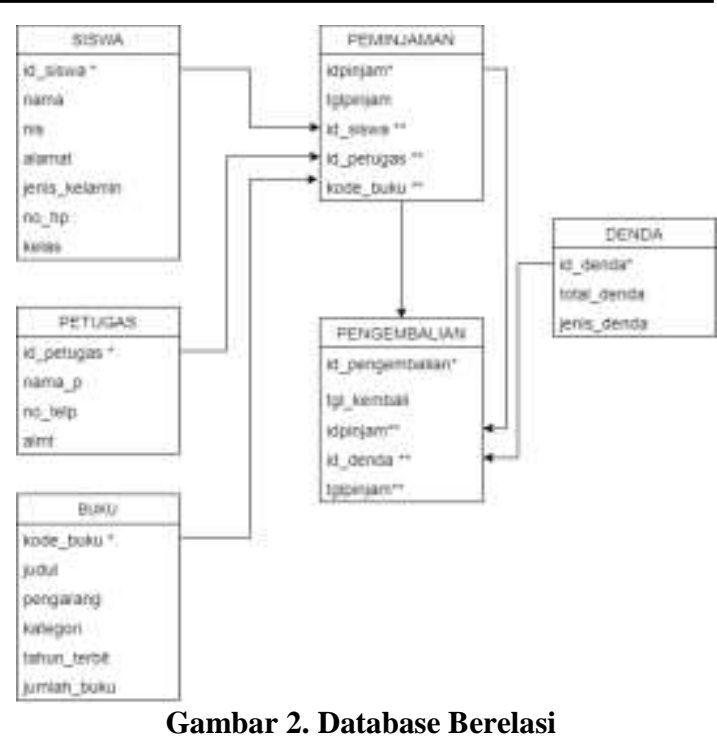

Pada aplikasi ini terdapat tabel siswa, petugas, buku, denda yang saling berelasi. Tabel siswa, petugas, buku dan pengembalian berelasi dengan tabel peminjaman, tabel denda berelasi dengan tabel pengembalian.

Tampilan Menu Sistem Informasi Pada Perpustakaan Madrasah Ibtidaiyah al Madinah

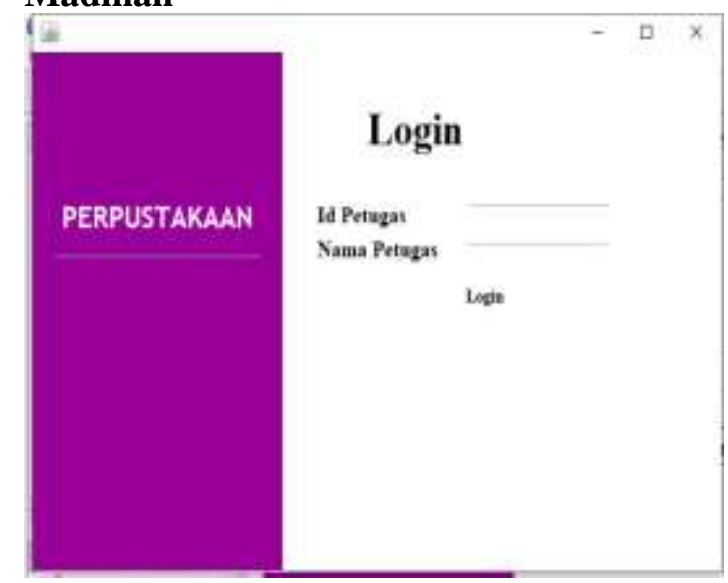

Gambar 3. Tampilan Menu Login

Menu login muncul saat akan memulai pengoperasian program. Id petugas dan nama petugas hanya boleh di isi oleh petugas yang bertugas. Petugas memasukan nama, id petugas agar bisa menjalankan sistem dan bisa menjalankan tabel siswa, tabel buku, tabel peminjaman, tabel pengembalian, tabel denda. Jika nama atau id tidak sesuai atau salah, maka akan muncul pemberitahuan bahwa id atau nama petugas salah. 


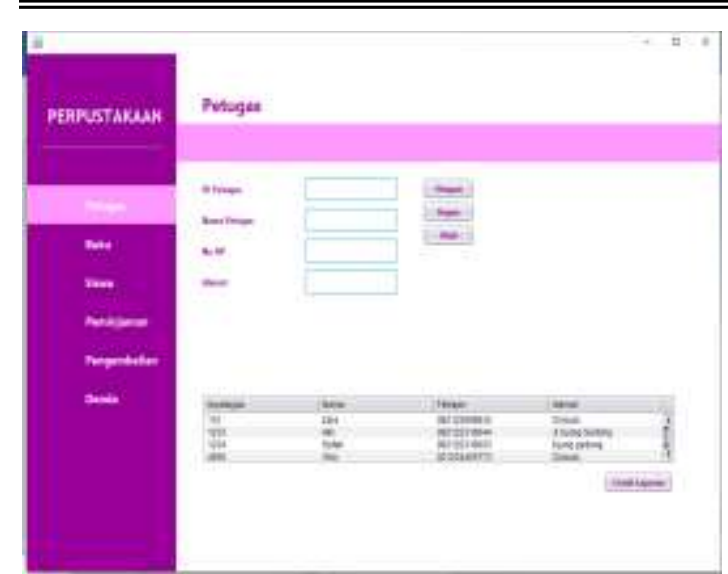

Gambar 4. Tampilan Menu Petugas

Menu petugas muncul setelah proses login berhasil. Id petugas, nama petugas, no hp, alamat hanya boleh diisi oleh petugas yang bertugas. Petugas memasukan nama, id, no $\mathrm{hp}$, alamat petugas agar bisa menjalankan sistem. Jika nama, id, no hp, dan alamat tidak sesuai, maka data yang di isikan tersebut yang akan muncul di tabel petugas.

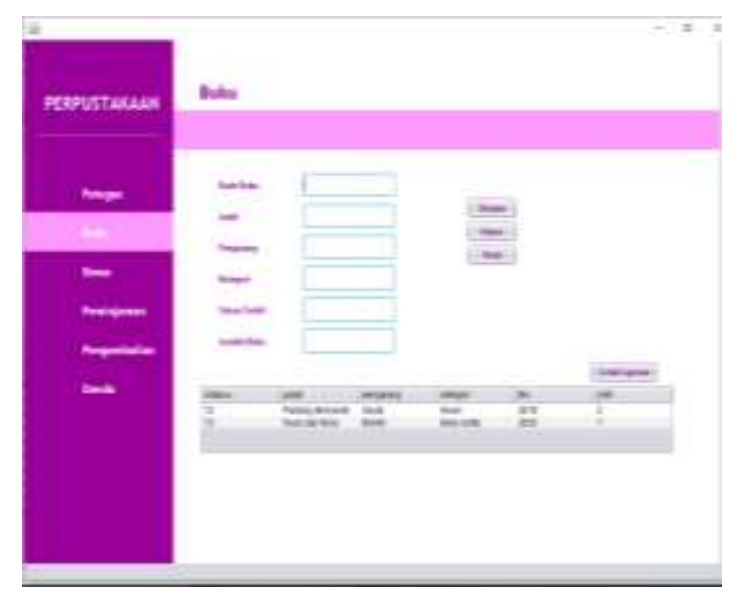

Gambar 5. Tampilan Menu Buku

Menu petugas muncul setelah proses login berhasil. Id petugas, nama petugas, no $\mathrm{hp}$, alamat hanya boleh diisi oleh petugas yang bertugas. Petugas memasukan nama, id, no $\mathrm{hp}$, alamat petugas agar bisa menjalankan sistem. Jika nama, id, no hp, dan alamat tidak sesuai, maka data yang di isikan tersebut yang akan muncul di tabel petugas. Dan agar data tersimpan ke dalam sistem dan database.

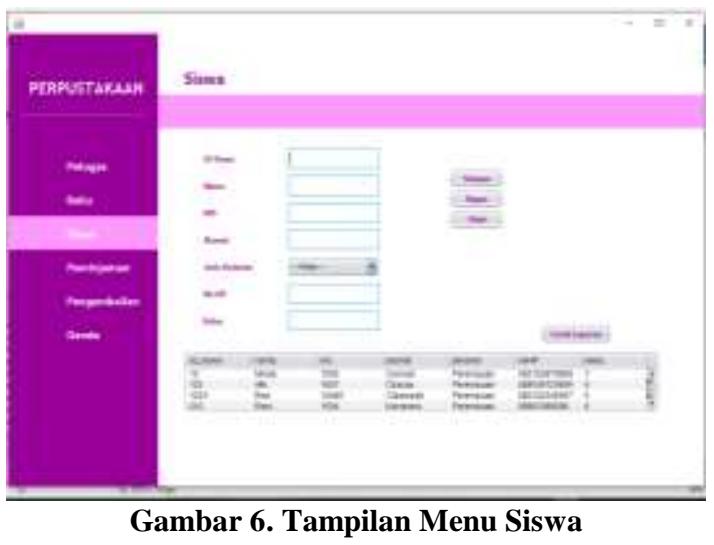

Petugas harus memasukan data yang di perlukan di dalam form siswa seperti id siswa, nama, nis, alamat, jenis kelamin, no hp, dan kelas. Agar data tabel yang akan muncul sesuai dan data tersimpan kedalam sistem dan database.

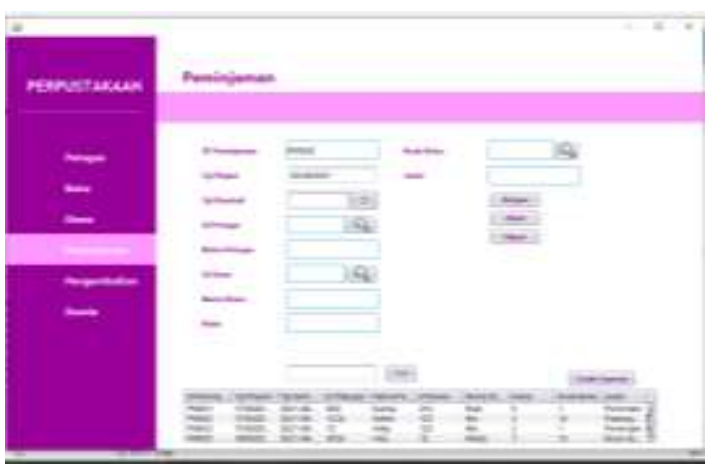

Gambar 7. Tampilan Menu Peminjaman

Petugas harus mengisi data yang di perlukan di dalam form peminjaman. Seperti mengambil data dari form petugas, mengambil data dari form siswa, dan mengambil data dari form buku. Agar data peminjaman bisa dicetak menjadi sebuah laporan.

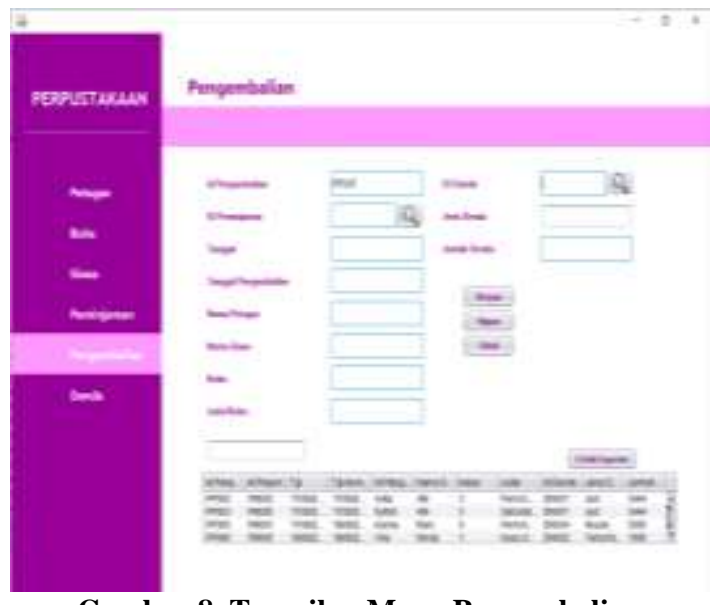

Gambar 8. Tampilan Menu Pengembalian 
Petugas harus mengisi data yang di perlukan di dalam form pengembalian. Seperti mengambil data dari form peminjaman, mengambil data dari form denda. Agar data pengembalian bisa dicetak menjadi sebuah laporan.
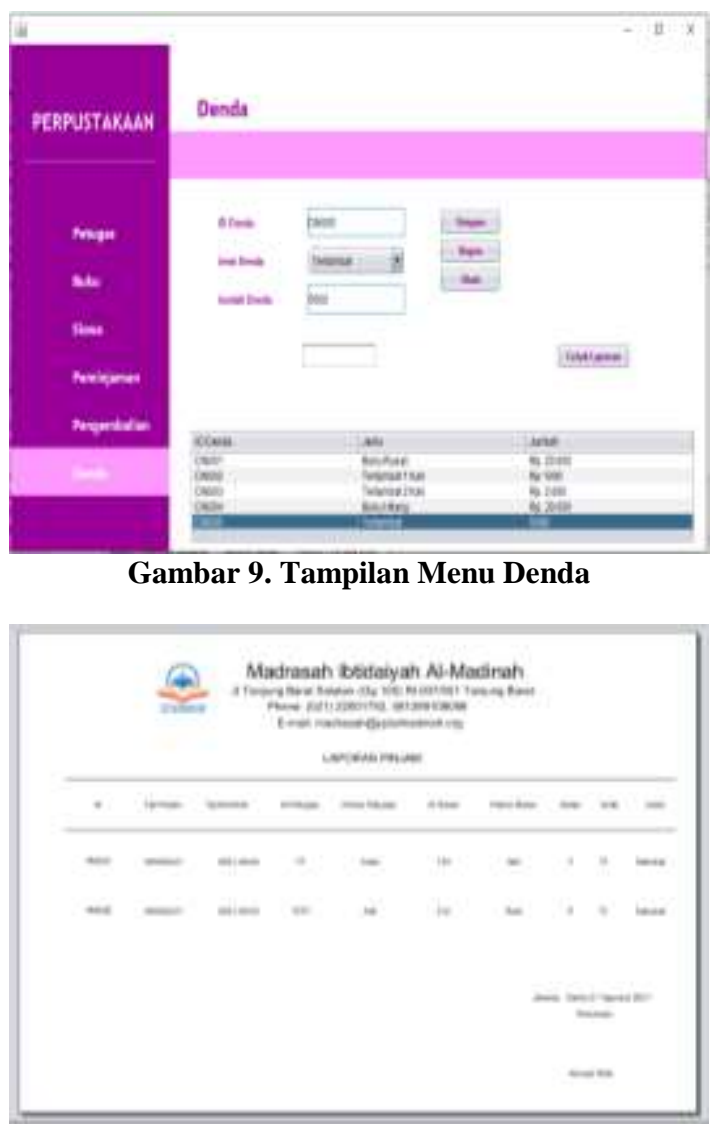

Gambar 10. Tampilan Menu Laporan Peminjaman

Petugas harus mengisi data yang di perlukan di dalam form peminjaman. Tampilan ini berisi data-data yang ada pada tabel data peminjaman dan memberikan informasi data siswa yang sudah melakukan peminjaman. Laporan peminjaman dibuat untuk kepala sekolah untuk mengetahui jumlah pinjaman pada perpustakaan.

\section{SIMPULAN DAN SARAN}

Setelah mengetahui keadaan sistem peminjaman buku di perpustakaan masih secara manual, maka dapat disimpulkan seperti berikut :

1. Aplikasi perpustakaan dapat membantu pekerjaan petugas perpustakaan menjadi lebih cepat dan mudah.

2. Dengan sistem terkomputerisasi dapat peningkatan kinerja.
3. Sistem informasi perpustakaan dapat membantu mengelola laporan data buku, laporan data siswa, laporan pinjam, laporan pengembalian dan laporan denda sehingga lebih mudah dalam pelaporan.

Setelah aplikasi ini diterapkan pada perpustakaan sekolah, proses peminjaman buku menjadi lebih tersusun, mudah, serta lebih efektif. Adapun saran yang penulis berikan sebagai berikut :

1. Membuat aplikasi perpustakaan yang sesuai dengan kebutuhan petugas dalam mengelola perpustakaan Madrasah Ibtidaiyah Al-Madinah.

2. Meningkatkan kinerja, karena tidak lagi menggunakan sistem manual dalam melaksanakan pengolahan data pada perpustakaan Madrasah Ibtidaiyah AlMadinah.

3. Untuk merancang sistem informasi agar membantu mengelola laporan data buku, laporan pinjam, laporan pengembalian, laporan siswa, dan laporan denda di Madrasah Ibtidaiyah Al-Madinah menjadi lebih akurat.

\section{DAFTAR PUSTAKA}

Binarso, Y. A., Sarwoko, E. A., \& Ba, N. bahtiar. (2012). Pembangunan Sistem Informasi Alumni Berbasis Web Pada Program Studi Teknik Informatika Universitas Diponegoro. Journal of Informatics and Technology, 1(1), 7284.

https://ejournal3.undip.ac.id/index.php/j oint/article/view/434

Darwati, I. (2017). Rancang Bangun Peminjaman Dan Pengembalian Buku Pada Perpustakaan Sekolah Dasar. Jurnal Ilmu Pengetahuan Dan Teknologi Komputer, 3(1), 139-144. http://ejournal.nusamandiri.ac.id/ejurnal /index.php/jitk/article/view/677/388

Hidayat, R., Marlina, S., \& Utami, L. D. (2017). Perancangan Sistem Informasi Penjualan Barang Handmade Berbasis Website Dengan Metode Waterfall. Simposium Nasional Ilmu Pengetahuan Dan Teknologi (SIMNASIPTEK) 2017, 4(978-602-61268-4-9), 342.

Nugraha, A. R., \& Pramukasari, G. (2017). Sistem Informasi Akademik Sekolah Berbasis Web Di Sekolah Menengah Pertama Negeri 11 Tasikmalaya. Jurnal 
Manajemen Informatika, 4(2), 1-10. https://www.cambridge.org/core/produc t/identifier/CBO9781107415324A009/t ype/book_part

Pratama, L. A. (2019). Perancangan Sistem Informasi Sirkulasi Buku Pada Perpustakaan SMP 103 Negeri Jakarta. STRING, 4(5), 227-234.

Prayitno, A., \& Safitri, Y. (2015). Peman faatan Sistem Informasi Perpustakaan Digital Berbasis Website Untuk Para Penulis. Advanced Materials Research, 1(1), 138-140. https://doi.org/10.4028/www.scientific. net/AMR.756-759.138

Putera, A. R., \& Ibrahim, M. (2018). Rancang Bangun Sistem Informasi Peminjaman dan Pengembalian Buku Perpustakaan SMP Negeri 1 Madiun. DoubleClick: Journal of Computer and Information Technology, $\quad$ 1(2), 57. https://doi.org/10.25273/doubleclick.v1 i2.2025

Rahmawati, N. A., \& Bachtiar, A. C. (2018). Analisis dan perancangan sistem informasi perpustakaan sekolah berdasarkan kebutuhan sistem. Berkala Ilmu Perpustakaan Dan Informasi, 14(1), 76. https://doi.org/10.22146/bip.28943

Rifani, E., Hartawan, R., \& Haroen, R. (2021). Pengaruh Pengembangan Aplikasi Pemetaan Visual Dan Pencatatan Pelanggan Terhadap Produktivitas Penagihan Pada PT.Telekomunikasi Indonesia. Jurnal Manajamen Informatika Jayakarta, 1(2), 73-95. https://doi.org/10.52362/jmijayakarta.v $1 \mathrm{i} 2.444$

Rumetna, M. S., Lina, T. N., \& Santoso, A. B. (2020). Rancang Bangun Aplikasi Koperasi Simpan Pinjam Menggunakan Metode Research and Development. Simetris: Jurnal Teknik Mesin, Elektro Dan Ilmu Komputer, 11(1), 119-128. https://doi.org/10.24176/simet.v11i1.37 31

Sutopo, P., Cahyadi, D., \& Arifin, Z. (2016). Sistem Informasi Eksekutif Sebaran Penjualan Kendaraan Bermotor Roda 2 di Kalimantan Timur Berbasis Web. Informatika Mulawarman: Jurnal Ilmiah Ilmu Komputer, 11(1), 23. https://doi.org/10.30872/jim.v11i1.199 